\title{
Human herpes virus 6 and endogenous biotin in salivary glands
}

\author{
M Green, L Sviland, C E Taylor, M Peiris, A L McCarthy, A D J Pearson, A J Malcolm
}

\begin{abstract}
Aims: To detect the presence of human herpes virus 6 (HHV6) and endogenous biotin in paraffin wax embedded and frozen salivary glands.

Methods: Two stage indirect and streptavidin-biotin immunoperoxidase techniques were used to visualise the antigens.

Results: HHV6 could not be shown in any of the tissues. However, considerable endogenous biotin antigenicity was detected in the glandular elements of the paraffin wax embedded material.

Conclusions: Results obtained with avidin-biotin detection systems should be interpreted with caution, especially when glandular epithelium is being stained. This may apply to both immunoperoxidase and in situ hybridisation techniques. The use of an anti-biotin antibody as a standard control should be considered.
\end{abstract}

HHV6 was first described in 1986, and since then studies have attempted to discover the sites of active or latent infection. Salivary glands have been implicated because of the high isolation rate of HHV6 from saliva. ${ }^{1}$ Two studies found virus at this site using both immunocytochemical and nucleic acid hybridisation techniques, and an avidin-biotin detection system. ${ }^{23}$

The increasing use of biotin labelled detection systems in recent years has led to improved sensitivity in many instances. However, the interpretation of results produced by this method relies on knowledge of the distribution and localisation of endogenous biotin. Kidney, liver, and pancreas contain sufficiently large amounts of endogenous biotin to pre-

Department of
Pathology
M Green
L Sviland
A L McCarthy
A J Malcolm
Department of
Virology
C E Taylor
M Peiris
Department of Child
Health
A D J Pearson
Royal Victoria
Infirmary, Queen
Victoria Road,
Newcastle upon Tyne,
NE1 4LP
Correspondence to:
Dr A M Malcolm
Accepted for publication
24 February 1992

Protocols used for archival salivary gland material clude the use of avidin-biotin detection systems, unless an avidin-binding blocking procedure is used. ${ }^{4}$

This paper describes an attempt to show the presence of HHV6 in paraffin wax embedded archival, and fresh frozen salivary gland tissues.

\section{Methods}

A total of 30 salivary gland paraffin wax blocks were examined, 24 of which were stained for HHV6 and 20 for biotin. A further 10 blocks of thyroid, parathyroid, breast, adrenal, pancreas and prostate tissue were examined for the occurrence of glandular cytoplasmic biotin localisation.

These blocks were used to: (1) investigate the effects of proteolytic digestion; (2) compare the results obtained by two and three stage immunoperoxidase techniques; (3) observe any staining due solely to the detection system used; and (4) compare detection sensitivities of frozen and paraffin wax tissues (table).

The 30 archival (post 1988) blocks of mainly serous salivary gland contained histologically normal tissue. All had been fixed in formolsaline, post-fixed in formol-sublimate and processed to paraffin wax. The 15 frozen blocks had been embedded in OCT (Miles), frozen in carbon dioxide, and stored at $-70^{\circ} \mathrm{C}$ until use. Frozen sections $(4 \mu \mathrm{m})$ were air dried overnight at room temperature.

Cells from the J-Jhan cell line, infected with the AJ strain of HHV6, were either fixed in formalin and processed to paraffin wax, or embedded in OCT and snap-frozen in liquid nitrogen, to produce positive control material. The staining controls comprised: (a) normal mouse serum (NMS) to replace the primary

\begin{tabular}{|c|c|c|c|c|}
\hline Digestion & $\begin{array}{l}\text { Primary } \\
\text { antibody }\end{array}$ & $\begin{array}{l}\text { Detection } \\
\text { system }\end{array}$ & $\begin{array}{l}\text { Number of } \\
\text { cases }\end{array}$ & Objective \\
\hline $\begin{array}{l}\text { None } \\
\text { None } \\
\text { None } \\
\text { None } \\
\text { None }\end{array}$ & $\begin{array}{l}\text { HHV6 (1 in 20) } \\
\text { HHV6 } \\
\text { None } \\
\text { None } \\
\text { Biotin }\end{array}$ & $\begin{array}{l}\text { Three stage sABC } \\
\text { Two stage ShaMPo } \\
\text { sABC only } \\
\text { sAPo only } \\
\text { Two-stage }\end{array}$ & $\begin{array}{l}14 \\
24 \\
14 \\
14 \\
30\end{array}$ & $\begin{array}{l}\text { Detection of HHV6 and } \\
\text { comparison of detection systems } \\
\text { Demonstration of endogenous } \\
\text { avidin binding } \\
\text { Detection of endogenous } \\
\text { biotin in } 20 \text { salivary glands } \\
\text { and } 10 \text { other tissue blocks }\end{array}$ \\
\hline $0 \cdot 1 \%$ trypsin 10 minutes, $37^{\circ} \mathrm{C}$ & HHV6 & Three stage & 6 & $\begin{array}{l}\text { Investigation of effects of } \\
\text { proteolytic digestion and } \\
\text { comparison of enzymes }\end{array}$ \\
\hline $0.1 \%$ pepsin in $0.1 \mathrm{M} \mathrm{HCl}$ & HHV6 & Three stage & 3 & \\
\hline
\end{tabular}




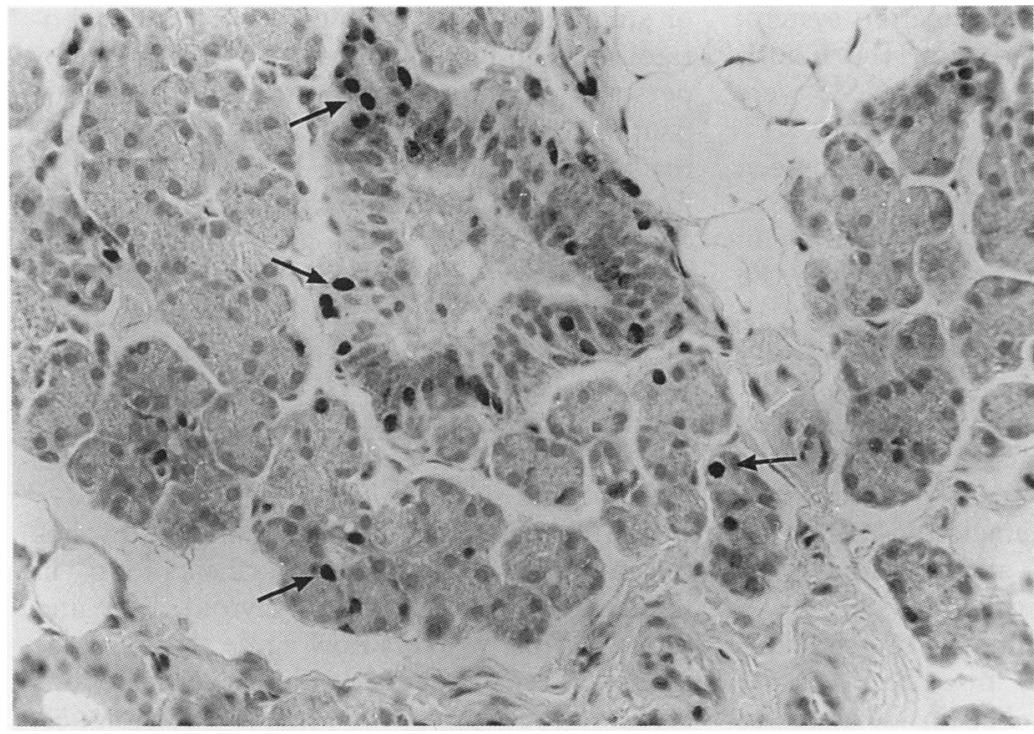

Figure 1 Nuclear positivity in peripheral serous acinar cells stained for HHV6 and detected with $s A B C$

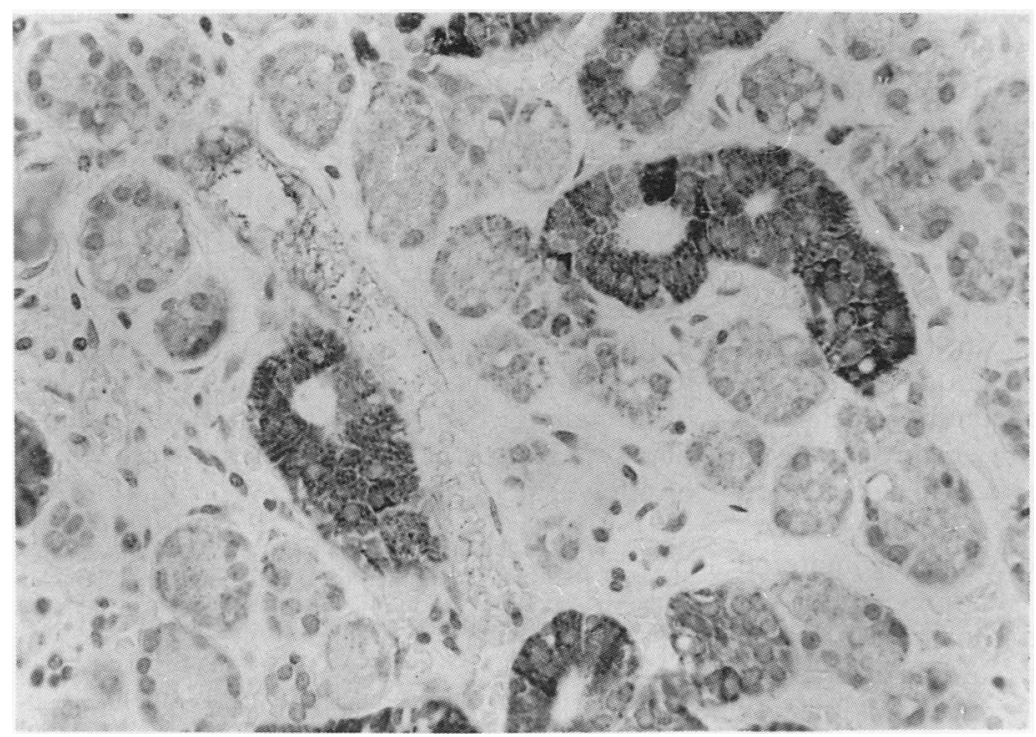

Figure 2 Cytoplasmic biotin in serous acini and ducts.

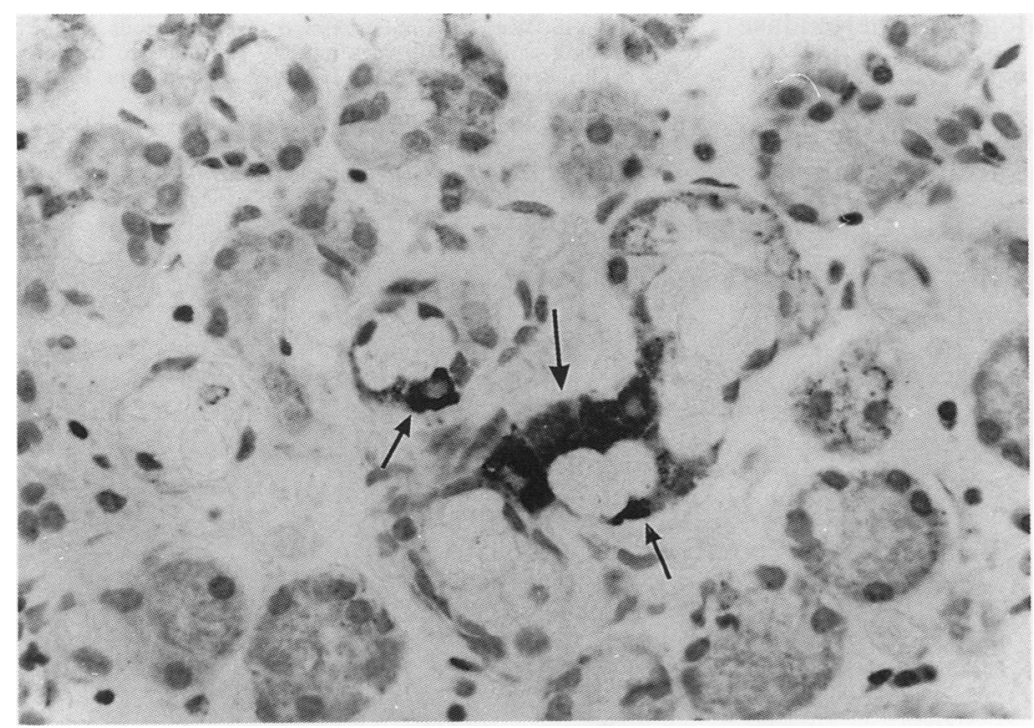

Figure 3 Cytoplasmic biotin in mucous acinar cells. antibody; (b) application of the peroxidase labelled stage only; and (c) non-infected J-Jhan cells stained for HHV6.

HHV6 was detected using a mixture of three mouse monoclonal antibodies, designated 6.1, 6.6, and 16.1, kindly supplied by $\operatorname{Dr} \mathrm{J} D$ Fox, Department of Medical Microbiology, University College and Middlesex School of Medicine. Each monoclonal was used at a dilution of 1 in 20 .

The rabbit-anti-mouse biotin conjugate, streptavidin-biotin-peroxidase complex (sABC), streptavidin-peroxidase (sAPo), and mouseanti-biotin-reagents were purchased from Dako Ltd. The sheep-anti-mouse peroxidase conjugate (ShaMPo) was supplied by Amersham.

Before immunostaining, the paraffin wax tissue sections were treated with $0.5 \%$ hydrogen peroxide in absolute methanol to inhibit endogenous peroxidase, digested with either (a) $0.1 \%$ porcine pancreatic trypsin (Sigma), $0.1 \%$ calcium chloride in $0.05 \mathrm{M}$ TRIS buffered saline (TBS), $\mathrm{pH} 7 \cdot 8$, or (b) $0 \cdot 1 \%$ pepsin (Sigma) in $0.1 \mathrm{M} \mathrm{HCl}$. They were then incubated with $5 \%$ normal lamb serum (NLS)

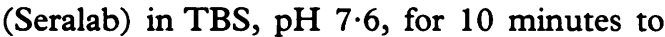
biock tissue Fc receptors.

The antibodies were diluted in $10 \%$ NLS in TBS, pH 7.6. Sections were incubated in the primary antibody for 45-60 minutes, and the secondary and tertiary antibodies for $30 \mathrm{~min}$ utes at room temperature. The sections were washed for 10 minutes between stages in $0.1 \%$ NLS in TBS, pH 7.6.

The reaction was visualised with a solution of $50 \mathrm{mg} \%$ 3,3'diaminobenzidine (BDH), $0.068 \%$ imidazole (Sigma), and $0.01 \%$ hydrogen peroxide in TBS, pH 7.6. A Mayer's haemalum counterstain was then applied.

For the frozen sections the antibody diluent was $10 \%$ NLS in PBS, pH $7 \cdot 1$, and the wash buffer was PBS with the addition of $0.1 \%$ NLS. The whole technique was carried out at room temperature except where indicated. Buffer washes of 10 minutes were carried out between each stage.

The air dried, unfixed sections were incubated successively in $10 \%$ NLS in PBS for 10 minutes, primary antibody for 60 minutes, fresh $10 \%$ formaldehyde in PBS for 20 minutes, $0.1 \%$ phenylhydrazine (Sigma) in PBS for 60 minutes at $37^{\circ} \mathrm{C}$ (to block endogenous peroxidase), sheep-anti-mouse peroxidase conjugate at 1 in 25 for 30 minutes, diaminobenzidine, then haemalum as for the paraffin wax sections.

\section{Results}

In all cases stained by the three-stage technique the reaction product was mainly localised to the cytoplasm of the duct lining cells. However, the same result was obtained from both the test sections and the NMS negative controls. Nuclear positivity was seen in two cases in cells at the edge of the section However, this seemed to be non-specific and may have been a fixation artefact, (fig 1).

The positive control material stained well for 
HHV6, independent of the detection system; non-infected cells incubated with HHV6 antisera and infected cells stained with NMS were uniformly negative.

Focal, cytoplasmic positivity was also seen when only the avidin-peroxidase (sABC or sAPo) reagents were applied. No staining of any kind was seen using the two-stage ShaMPo system.

Biotin was detected in all the 20 salivary glands stained. Staining was intense in the cytoplasm of the duct lining cells, scattered serous acini and mucous acinar epithelial cells (figs 2 and 3). In the six further non-salivary gland tissues biotin was detected in the gland/ duct/follicle lining cells and in interstitial macrophages and plasma cells.

The use of trypsin eliminated the spurious nuclear staining but had no effect on the salivary duct positivity. Pepsin seemed to increase the level of avidin binding. However, pepsin greatly reduced the positivity of the HHV6 stained J-Jhan cells. Neither above digestion protocol, nor that suggested by Fox et $a l^{2}(0.4 \%$ pepsin for $20-30$ minutes), produced any unequivocal staining for $\mathrm{HHV} 6$.

The 15 assorted frozen submandibular, parotid, and minor salivary glands were uniformly negative for HHV6, although the control cells were well stained by the technique used.

\section{Discussion}

Fox et al found HHV6 by in situ hybridisation and immunocytochemistry in the nuclei of serous cells and in both the nuclei and cytoplasm of mucous and duct columnar cells in a high proportion of the salivary glands studied. ${ }^{2}$ We were not able to reproduce these results in either paraffin wax or frozen sections. However, we have shown avidin-binding material and non-specific nuclear staining in most of the above sites. Contrary to the findings of Fox et al was the almost total loss of HHV6 staining after pepsin digestion of sections of infected J-Jhan cells. This would indicate that pepsin destroys the HHV6 antigen in infected cell culture material and presumably in tissue sections also. Methanol-peroxide and phenylhydrazine inhibition of endogenous peroxidase had no effect on the demonstration of HHV6.

These discrepancies may be due to the use of different antibodies, tissue fixation regimens, or staining protocol. Other work in our laboratory on mouse kidney ( $\mathrm{F} H$ Carpenter, personal communication) suggests that tissue fixation has an important role in subsequent reactivity with anti-biotin. Primary fixation in formol-sublimate resulted in no demonstrable endogenous biotin; with Carnoy's and Bouin's fixatives tissue contained large amounts. With formalin the endogenous biotin was intermediate but reduced further as the time of fixation increased. Thus studies describing results derived from the use of avidin-biotin complex (ABC) detection systems should state the type and duration of tissue fixation.

In $1981 \mathrm{Hsu}$ et al claimed that "no unwanted staining is derived from intrinsic biotin" in their test tissues, including thyroid, liver and breast. $^{5}$ Most workers now agree that of those tissues, liver contains sufficient endogenous biotin to cause problems with $\mathrm{ABC}$ techniques, and we have further shown the presence of intrinsic avidin binding material not only in thyroid and breast but also a range of glandular tissues.

Although the intensity of non-specific staining produced by the avidin-biotin technique was less than that seen in the positive controls or the biotin stained sections, it was still above background levels and could be mistaken for positivity. This must place constraints on the interpretation of results obtained using biotinylated antibodies or cDNA probes, and emphasises the need for strict controls.

The use of the anti-biotin antibody showed the extent of endogenous biotin in the tissues tested, and this antibody would provide an ideal staining control for avidin-biotin detection systems, especially when results are weak or equivocal.

We thank the Tyneside Leukaemia Research Fund, the Scientific and Research Committee of Newcastle District Health Authority, and the North of England Children's Cancer Authority, and the North of Eng
Research Fund for financial support.

1 Harnett GB, Farr TJ, Pietroboni GR, Bucens MR. Frequent shedding of human herpes virus 6 in saliva. $\mathcal{f}$ Med Viro 1990;30:128-30

2 Fox JD, Briggs M, Ward P, Tedder RS. Human herpes virus 6 in salivary glands. Lancet 1990;336:590-3.

3 Krueger GRF, Wasserman K, De Clerck LS, et al. Latent herpes virus- 6 in salivary and bronchial glands. Lancet 1990;336:1255.

4 Wood GS, Warnke R. Suppression of endogenous avidin binding activity in tissues and its relevance to biotinavidin detection systems. F Histochem Cytochem 1981; 29:1 196-204.

5 Hsu SM, Raine L, Fanger H. Use of avidin-biotinperoxidase complex (ABC) in immunoperoxidase technique. $\mathcal{J}$ Histochem Cytochem 1981;29:577-80. 